\title{
REACTION TIME AS A MEASURE OF THE TEMPORAL RESPONSE PROPERTIES OF INDIVIDUAL COLOUR MECHANISMS
}

\author{
J. D. Mollon ${ }^{1}$ and J. Krauskopf \\ Department of Experimental Psychology, Oxford University, Oxford, U.K. and Bell Laboratories, \\ Murray Hill, New Jersey, U.S.A.
}

(Received 30 May 1972)

INTRODUCTION

IT HAS often been suggested, and often denied, that the different colour mechanisms of the human eye respond with different latencies (Helmholtz, 1922; ChaRPenTIER, 1893; IVES, 1917, 1918; WALRAVEN and LeEBEEK, 1964) and the hypothesis has notably been invoked in explanation of the Fechner-Benham subjective colours (COHEN and GORDON, 1949). Thus PIÉRON (1923) claimed that time constants were greater for the blue-sensitive cone mechanism than for the green, and greater for the green than for the red. Experimental estimates of latency have been derived from several different psychophysical procedures, but the results have been ambiguous and contradictory. PIÉRON (1932a, b) substituted monochromatic pulses for an achromatic field of the same brightness and found that reaction times to red $(640 \mathrm{~nm})$ pulses were slightly shorter than those to blue $(475 \mathrm{~nm})$; and LIANG and PIÉRON (1947), estimating latencies from the magnitude of the Pulfrich stereo effect, reported similar differences. On the other hand, Holmes (1947), PoLLACK (1968) and LrT, YOUNG and SHAFFER (1971), measuring reaction times to monochromatic stimuli, and GuTH (1964), using a moving, bipartite target, failed to find differences between wavelengths at photopic intensities.

In almost all previous studies of this question coloured stimuli of supra-threshold intensity have been presented on achromatic backgrounds. Such stimuli will excite a single cone mechanism only under a very restricted range of conditions. In the present experiments we have isolated the responses of individual chromatic mechanisms by means of the twocolour increment threshold procedure developed by STILES $(1939,1953,1959)$.

A second difficulty in interpreting and comparing earlier studies arises because the response to a physically punctate stimulus will almost certainly be dispersed, temporally and spatially, within the visual system. It is unlikely that different psychophysical measures of sensory latency will be related to the same element of the neural response (cf. STERNBERG and KNOLL, 1972). In the first experiment described below, reaction times were measured for liminal monochromatic flashes presented on monochromatic backgrounds; and the probability that a flash would be seen, and responded to, was held constant as,stimulus conditions were varied. As a working hypothesis we suppose that a brief stimulus of liminal intensity generates a slow, graded response at a very early stage of the visual system and that later neural events are triggered ballistically if and when a threshold amplitude is reached. If

\footnotetext{
' Present address: The Psychological Laboratory, University of Cambridge, Downing Street, Cambridge.
} 
test stimuli presented under different conditions are all of threshold intensity, then variations in the measured reaction time should reflect variations in the time required for the initial response to reach its peak value. ${ }^{2}$

There is much experimental evidence that the time constants of retinal processes are inversely related to the level of light adaptation ${ }^{3}$ and in the models of FUORTES and HODGKIN (1964), SPERLING and SONDHI (1968) and MATIN (1968) adaptation is achieved through the parametric control, by feedback or feedforward, of the time constants of the system. Now, Stilcs' measurements demonstrate that the adaptive states of the individual chromatic mechanisms ( $\pi$ mechanisms) are essentially independent: the sensitivity of a particular mechanism depends only upon the number of quanta absorbed from the background by that mechanism. For, in those parts of the spectrum where the comparison can be made, the field sensitivity of each mechanism, derived by manipulating the adaptation wavelength $(\mu)$, coincides closely with the test sensitivity, which is derived by manipulating the test wavelength $(\lambda)$. Thus the traditional question of whether the individual colour mechanisms have different time constants may not admit of an absolute answer and it may be more meaningful rather to ask whether their time constants vary independently. The present study tests the hypothesis that reaction times will vary with the adaptive state only of the $\pi$ mechanism mediating the response and not with that of the retina as a whole. A similar prediction bas recently been confirmed for the critical duration, or limit of time-intensity reciprocity, for the detection of brief flashes (KRAUSKOPF, 1969; KRAUSKOPF and MOLLON, 1971; UETSUKI and IKEDA, 1971).

\section{EXPERIMENT 1}

\section{Method}

In its logic Experiment 1 was analogous to the experiments on critical durations reported earlier (KrausKOPF and MOLLON, 1971). The principle was to manipulate the adaptive states of individual $\pi$ mechanisms by means of background wavelengths to which they were differentially sensitive, measure reaction times for liminal targets at a series of background intensities and determine whether reaction time varied only with the adaptive state of the mechanism mediating a particular detection. On the basis of Stiles' published data (WYSZECKI and STILES, 1967) combinations of test and background wavelengths were chosen to provide conditions under which one $\pi$ mechanism is much more sensitive to the test flash than are the others and so is alone responsible for its detection.

The apparatus and procedure were very similar to those described earlier (KraUSKOPf and MoLLON, $o p$. cit.) and will be outlined here only briefly. Light from two ribbon-filament lamps wired in series with a constant d.c. supply was delivered to the subject's right eye through a two-channel Maxwellian-view system. The test fiash was a monochromatic disc subtending $1^{\circ}$ of visual angle and was presented to the centre of the fovea. The adaptation field was a concentric disc subtending $3^{\circ}$. The duration of the test flash was $10 \mathrm{msec}$ and its wavelength $(\lambda)$ was 430,500 or $650 \mathrm{~nm}$. The wavelength of the adaptation field $(\mu)$ was either 500 or $600 \mathrm{~nm}$. The duration, wavelength and intensity of the stimuli and the rate and sequence of stimulus presetattion were controlled on-line by a small digital computer. A silent shutter, a vane rotated by a stepping monor, replaced the double-vane shutter used in the earlier experiment.

Each experimental session was devoted to one of the six possible combinations of test and background wavelengths. Each combination was tested in four separate sessions and the order of conditions was randomised. A session began with a dark-adaptation period lasting two minutes. Data were gathered first with the eye dark-adapted and then at five background levels, which increased in intensity by steps of 1 log unit. The

2 The primary comparisons of Experiment 1 are concerned with equivalence of reaction times and are not critically dependent on the validity of these assumptions.

${ }^{3}$ For example, the peaks of temporal modulation transfer functions shift to higher stimulus frequencies as the mean luminance is raised (DE LANGE, 1958a); the critical duration for the detection of stimulus increments decreases as a function of background intensity (HERRICK, 1956; BARLOW, 1958) and an analysis of the Pulfrich effect, which is traditionally interpreted as a measure of sensory latency, reveals a similar relation (ALPERN, 1968). 
lowest intensity of the $300 \mathrm{am}$ adaptation field was $-4 \cdot 8 \log \mathrm{erg} / \mathrm{deg}^{2} / \mathrm{sec}$, that of the $600 \mathrm{~nm}$ field was $-4 \cdot 4$ $\log \mathrm{erg} / \mathrm{deg}^{2}$ isec. At each new background level the experimental measurements were preceded by an adaptation period of 2 min.

The procedure used earlier to measure increment thresholds (KrausKopf and MoLLON, 1971) was modified in such a way that the subject's responses gave concomitant estimates of threshold and reaction time. For each background condition an initial estimate of the threshold for 50 per cent detection was obtained as before by Yes-No responses to six preliminary stimuli. A multiple-staircase method was then used to reach a final value for the threshold, but the subject was now required not to respond Yes or No but to press a single key as rapidly as possible whenever he saw a flash.

A single stimulus-response cycle proceeded as follows. A 200 -msec pre-warning tone was presented after an initial delay of $3 \mathrm{sec}$ and a similar warning tone was presented after a fu rther delay of $1 \mathrm{sec}$. The 10-msec test-flash was delivered $1 \mathrm{sec}$ after the second warning tone. The subject was allowed $2 \mathrm{sec}$ in which to respond. If he did respond, the time elapsed after the offset of the flash was recorded as the reaction time and a fresh cycle was begun. Failure to respond within $2 \mathrm{sec}$ was treated as a negative response for the purpose of estimating the threshold and a new cycle was begun at the end of this interval. On 25 per cent of the trials, randomly determined, no stimulus was presented. To ensure that the subject did not discriminate blank and positive trials by any vibrational cue, the motor carrying the shutter vane was stepped backwards on blank trials.

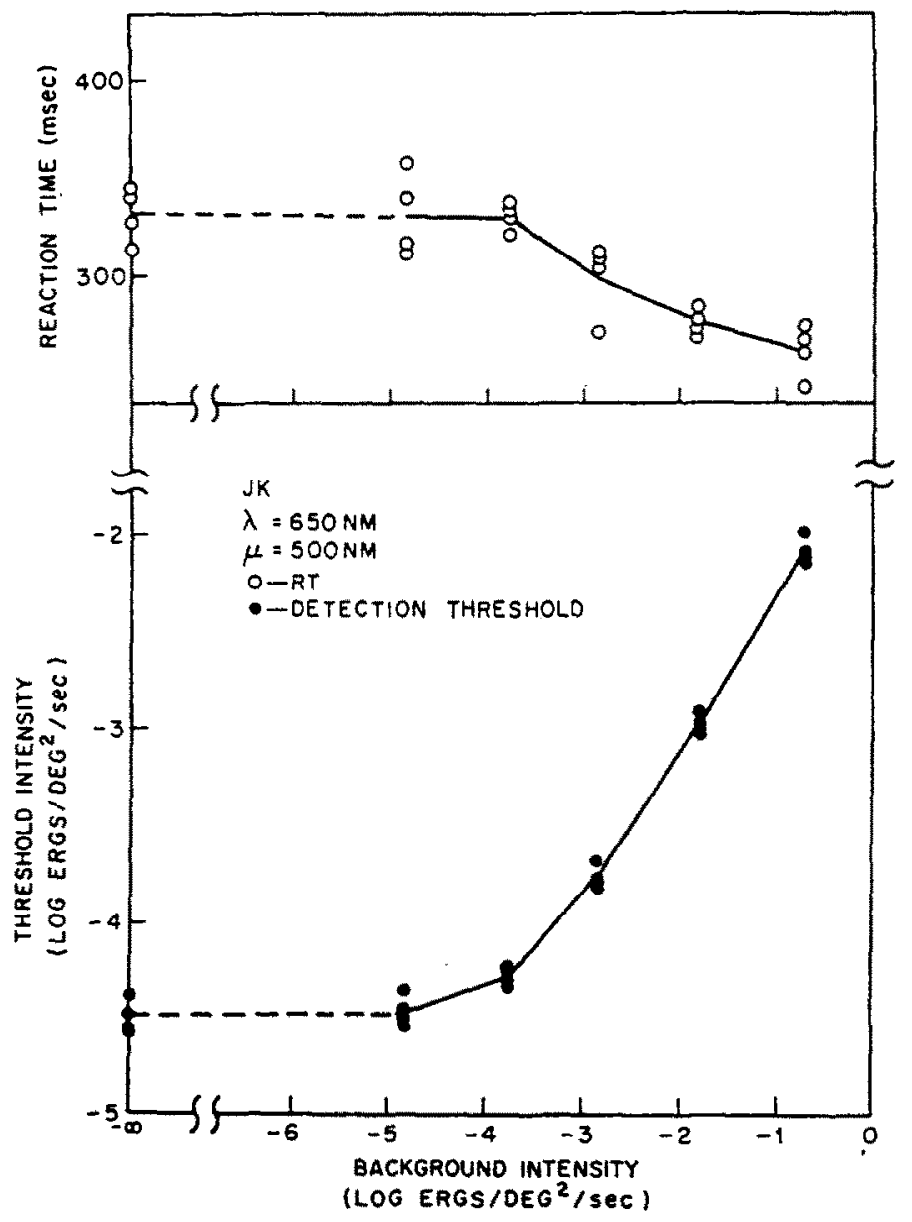

Fig. 1. The lower panel shows increment thresholds as a function of background intensity when $\lambda=650 \mathrm{~nm}$ and $\mu=500 \mathrm{~nm}$. The upper panel shows the corresponding reaction times. Results from four separate experimental sessions are presented in order to illustrate variability. Observer: JK. 


\section{Results}

Figure 1 shows typical results for one combination of test and background wavelengths. The lower points represent the threshold for the test flash at each background intensity and the corresponding points in the upper panel represent median reaction time. ${ }^{4}$ Each point corresponds to an individual session and the lines are the means of four sessions for one subject. The threshold curve resembles a conventional incrementthreshold function and is very similar to the 10 -msec function found for this condition in the critical duration experiment (KRAUSKOPF and MOLLON, 1971, Fig. 2). It can be seen that reaction time shortens as the threshold rises.

We wish to determine whether reaction time depends upon the adaptive state of the retina as a whole or only upon the adaptive state of the $\pi$ mechanism mediating the response. Figures 2 and 3 allow us to judge which of these hypotheses better predicts the experimental results. Both figures show the results for the various combinations of test $(\lambda)$ and background $(\mu)$ wavelengths, but the abscissae differ. Figure 2 shows the relation

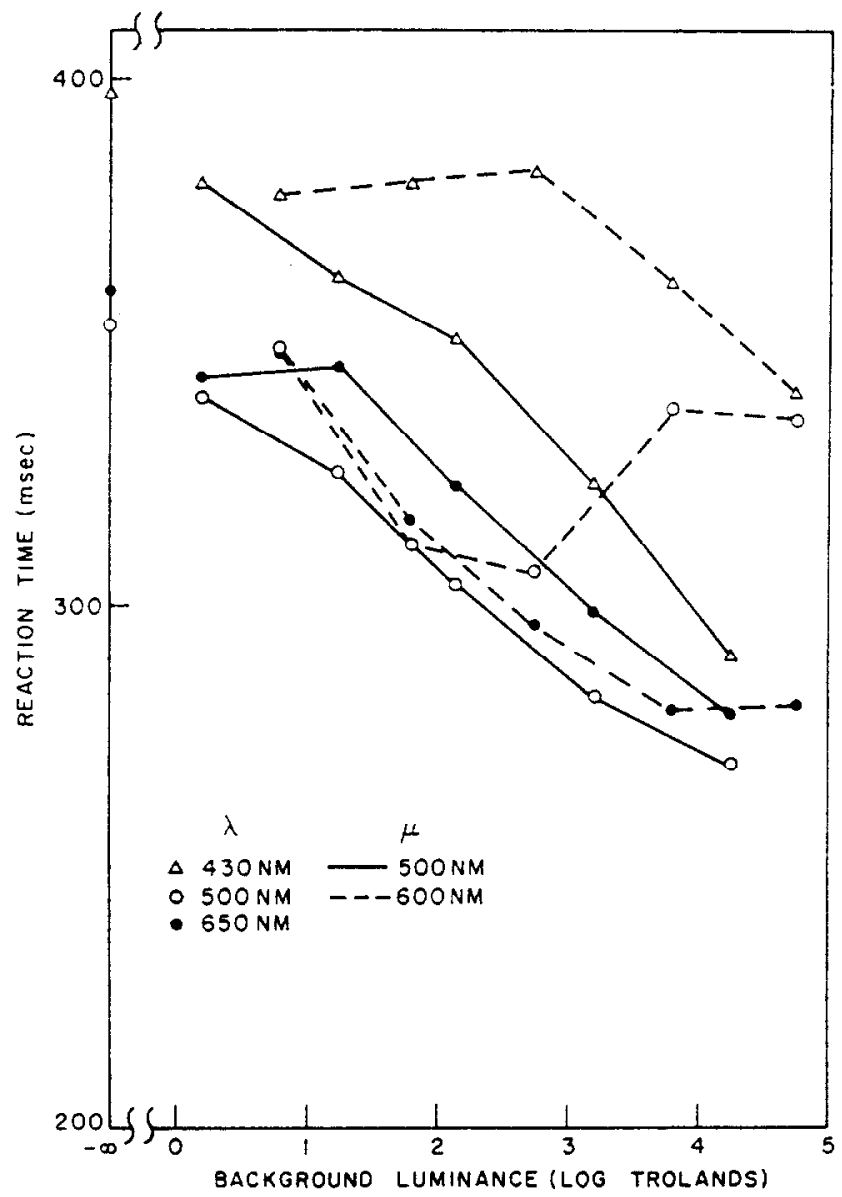

Fig. 2. Reaction times as a function of the luminance of the adapting field. The results are the means for two observers.

4 Since frequency distributions of reaction times are typically found to be skewed, the median is the preferable measure of central tendency and the results are plotted in these terms. However, both median and mean reaction times were calculated for all conditions. The results of the two analyses do not differ in any qualitative way. The false positive rate was approximately 3 per cent. Occasional reactions of less than $150 \mathrm{msec}$ were classed as anticipations and excluded. 
of median reaction time to log background luminance. It can be seen from this type of plot that reaction times shorten, for all but one condition, as background intensity rises; but there is no clear relation between reaction time and the luminance of the adapting field. Reaction time therefore does not appear to depend on the adaptive state of the retina as a whole. If the latter were the case, reaction time functions for the same test wavelength but different background wavelengths should be superimposed when plotted against photopic luminance. No adaptive mechanism with a single spectral sensitivity function (whether or not equivalent to the photopic luminosity function) could account for the results, since a change in background wavelength from 500 to $600 \mathrm{~nm}$ does not displace the reaction time function for each test wavelength by a constant amount, or in a constant direction.

In order to test the alternative hypothesis that reaction time varies only with the adaptive state of the particular $\pi$ mechanism mediating the response, reaction times are plotted in Fig. 3 as a function of sensitivity. Log sensitivity is defined as the difference between the log absolute threshold for the test flash and its threshold at a particular background level (note that log sensitivity decreases to the right in Fig. 3). For comparison, critical durations from the earlier experiment, expressed here in linear units, are plotted in the same figure. ${ }^{3}$

In the case of 430 and $650 \mathrm{~nm}$ test flashes the pairs of reaction-time functions coincide well when plotted against sensitivity and so support the hypothesis that reaction time depends upon the adaptive state of the colour mechanism mediating the detection rather than upon that of the retina as a whole. On the basis of Stiles' analysis the results for the $650 \mathrm{~nm}$ test flashes may be wholly attributed to the red mechanism, $\pi_{3}$.
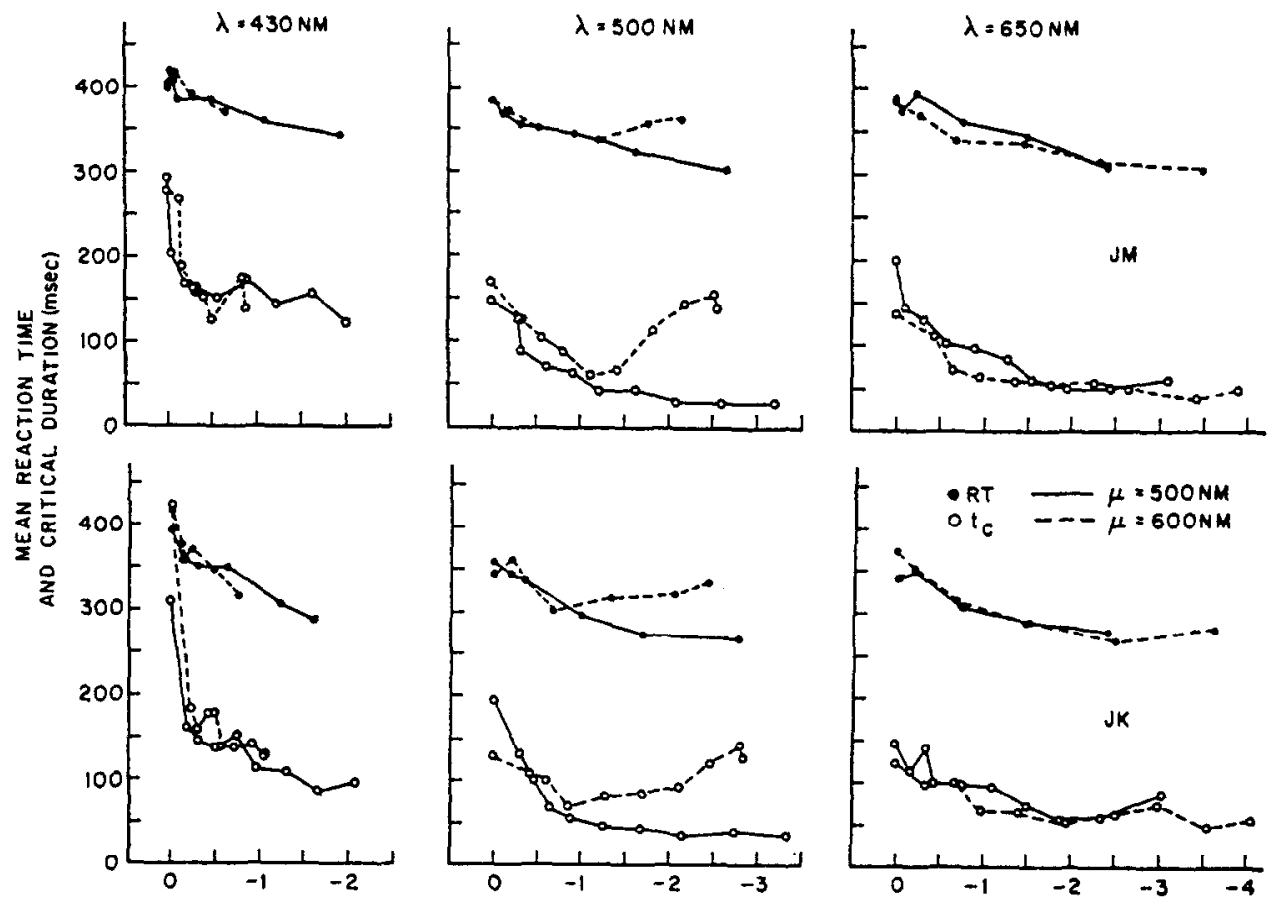

LOG SENSITIVITY (RE ABSOLUTE THRESHOLO)= LOG $\left(E / E_{0}\right)$

FIG. 3. Mean reaction time and mean critical duration as a function of log sensitivity. In each panel are shown results for one test wavelength and two background wavelengths. Within a panel, results for $500 \mathrm{~nm}$ backgrounds are connected by a continuous line and those for $600 \mathrm{~nm}$ backgrounds by a dashed line. Values for the critical duration, $t_{f}$, are taken from KRAUSKOPF and MoLLoN (1971) and are shown here for comparison. Note that sensitivity decreases to the right.

\footnotetext{
3he critical duration, or limit of time-intensity reciprocity for a constant probability of detection, was estimated from the difference between the thresholds for very short and very long flashes. For details see KRAUSKOPf and MOLLON (op. cit.).
} 
Similarly those for $430 \mathrm{~nm}$ targets can be attributed to $\pi_{1}$ at moderate background intensities, but detection may depend upon the secondary blue mechanisms, $\pi_{2}$ and $\pi_{3}$, at lower and higher intensities respectively. ${ }^{5}$ Reaction times to $430 \mathrm{~nm}$ targets, at least at the lower adaptation intensities, appear to be longer than those to red targets, but the primary finding that the time constants of individual mechanisms vary independently makes difficult any absolute comparison of different cone mechanisms. Such comparison should be specific to target size and other stimulus conditions.

The results for $500 \mathrm{~nm}$ targets appear anomalous: not only is the variation of reaction time dependent on the adaptation wavelength, but also reaction time actually increases when the $600 \mathrm{~nm}$ background is of high intensity. However, this seeming discrepancy, which is also apparent in the critical duration results, is in fact predicted by Stiles' model. For Stiles suggests that $500 \mathrm{~nm}$ test flashes presented on $600 \mathrm{~nm}$ backgrounds are detected by the green mechanism, $\pi_{\downarrow}$, only at relatively low adaptation intensities. At higher background levels detection is mediated by $\pi_{1}$ (STILES, 1953). Since $\pi_{1}$ is relatively insensitive to $600 \mathrm{~nm}$ backgrounds, its adaptive state, and thus the time constants of its response, will be relatively little changed from their darkadapted values when it begins to mediate the detection of $500 \mathrm{~nm}$ targets. Moreover, the reaction times to $430 \mathrm{~nm}$ test flashes suggest that there may be a primary difference between the time constants of $\pi_{1}$ and $\pi_{4}$ when their sensitivities are equated.

If the reason that the $500 \mathrm{~nm}$ functions diverge in Fig. 3 is indeed that detection depends upon $\pi_{1}$, rather than $\pi_{4}$, when the $600 \mathrm{~nm}$ background is of high intensity, then it should be possible to abolish the anomaly by choosing stimulus conditions that raise the threshold of $\pi_{1}$ relative to that of $\pi_{4}$. In Experiment 1 the test

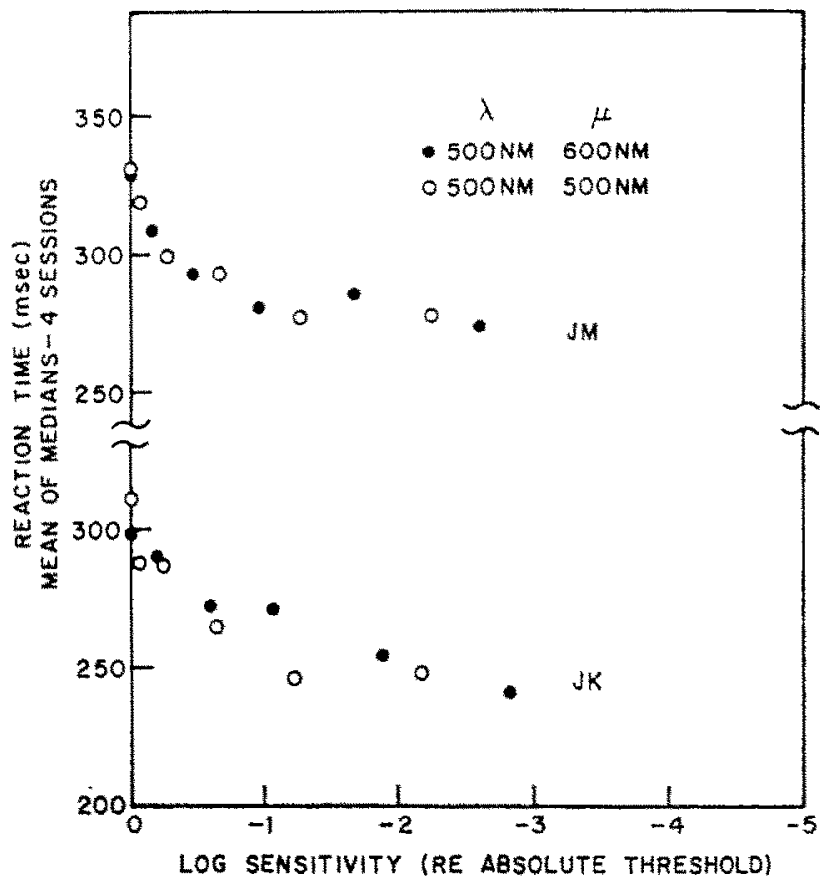

Fro. 4. Reaction times for $6^{\prime \prime}$ test-flashes when $\lambda=500 \mathrm{~nm}$ and $\mu=500$ or $600 \mathrm{~nm}$. Means of medians are shown for each subject.

${ }^{6}$ The mechanism responsible for detection of $430 \mathrm{~nm}$ targets at absolute threshold requires some consideration. In the present case we can probably exclude the possibility that the blue targets presented to the dark-adapted fovea were detected by the rods. In view of the very difference in time constants, the mechanism mediating detection at RL for $500 \mathrm{~nm}$ targets cannot be the same as that mediating detection of $430 \mathrm{~nm}$ targets. Yet Stiles has shown that the spectral sensitivity curves for $\pi_{4}$ and $\pi_{0}$ run nearly parallel between 430 and $500 \mathrm{~nm}$ (cf. STILEs, 1953, Fig. 20). Therefore, the $430 \mathrm{~nm}$ targets must be detected by a mechanism that is more sensitive at this wavelength than $\pi_{4}$, and a fortiort, more sensitive than $\pi_{0}$.

According to the model developed by Stiles, the independent mechanism $\pi_{2}$ is responsible, in some observers, for the detection of short-wavelength flashes when background intensity is low. Our own auxiliary measurements of increment thresholds suggest that JDM falls into this class of observer. The evidence for $\mathrm{JK}$ is ambiguous. 
flash subtended $1^{2}$. It is known that the $\pi_{1}$ threshold is disproportionately high for small test flashes delivered to the central fovea (StILES, 1949; BrINDLEY, 1954). In a second experiment, therefore, reaction times were measured for inuch smaller $500 \mathrm{~nm}$ targets.

\section{EXPERIMENT 2}

The procedures and conditions of this experiment were exactly the same as those of Experiment 1 except that only $500 \mathrm{~nm}$ targets were used and the test flashes subtended $6^{\prime}$.

Median reaction times for small $500 \mathrm{~nm}$ targets are plotted in Fig. 4 as a function of log sensitivity. The coincidence of the functions obtained with 500 and $600 \mathrm{~nm}$ backgrounds suggests that the divergence found in Experiment $l$ can indeed be attributed to the intervention of $\pi_{1}$. It appears that the reduction of target size has raised thresholds for $\pi_{1}$ more than those for $\pi_{4}$, and that $500 \mathrm{~nm}$ targets presented on $600 \mathrm{~nm}$ fields are now detected by $\pi_{4}$ at all the background intensities used.

We conclude that reaction times to threshold targets are inversely related to the adaptive state of the chromatic mechanism that mediates the response. This independence reveals a fresh feature of the psychophysically-detined $\pi$ mechanisms and illustrates the predictive value of Stiles' model. Since interactions between cone mechanisms are known to occur at a relatively early stage in the primate visual system, and certainly by the inner nuclear layer of the retina, (Gouras, 1968), our experiments suggest that the changes in time constants that are associated with, and probably intrinsic to, changes in adaptive state arise at a very distal stage of the visual system.

The present results show that reaction times for liminal blue targets at the dark-adapted level are longer than those for green and red targets. Since previous investigators have reported that variation of wavelength produces little or no difference in the reaction time to supra-threshold targets of equal luminosity, a third experiment was performed to show empirically that under conditions similar to those of Experiment 1 reaction times for red and blue targets will converge towards a similar value as target intensity is increased above its threshold level.

\section{EXPERIMENT 3}

The apparatus described above was used to measure reaction times for $430 \mathrm{~nm}$ and $650 \mathrm{~nm}$ targets of varying intensity. The test flashes subtended $1^{\circ}$, were presented on a dark background, and were terminated by the subject's response.

Measurements were made in eight sessions, four devoted to each wavelength. The order of wavelengths was counterbalanced. A range of ten intensities was used in each session and the lowest intensity corresponded to the threshold for 50 per cent detection. This jatter value was determined by means of the multiple-staircase, Yes-No procedure described earlier (KRAUSKOpF and MoL.LON, 1971), and was established at the beginning of the first session devoted to a particular wavelength.

Each session began with a dark adaptation period lasting $2 \mathrm{~min}$. Reaction times were measured in five blocks separated by $15 \mathrm{sec}$ intervals. Within each block, five stimuli were presented at each intensity. The order of intensities was randomised without replacement. 9 per cent of the triais were blank. Each positive trial consisted of the following sequence of events: I sec delay; $200 \mathrm{msec}$ pre-warning tone; I sec delay; $200-\mathrm{msec}$ warning tone; $1 \mathrm{sec}$ delay; onset of stimulus. The stimulus was terminated either when the subject responded or after $2 \mathrm{sec}$ if no response had been made during this interval. The interval between the onset of the stimulus and the subject's response was recorded as the reaction time.

Median reaction times to red and blue targets of varying intensity are shown in the upper panels of Fig. 5. The abscissa is stimulus intensity plotted relative to the absolute threshold for the corresponding wavelength. It is clear that the difference between wavelengths, which is plotted in the middle panels, declines rapidly and becomes very small at high intensities. Standard deviations, which also fall as a function of stimulus intensity, are shown in the lowermost panels.

Why is the effect of wavelength on reaction time almost completely abolished at higher intensities? Two possibilities suggest themselves:

(a) Reaction times for all chromatic mechanisms may converge towards the same asymptotic value as stimulus intensity is increased.

(b) The time constants of the short-wavelength mechanisms may remain greater even at asymptotic values, but, as the $430 \mathrm{~nm}$ targets are increased in intensity, $\pi_{4}$ and $\pi_{3}$ will contribute to the response and the reaction times measured may be those for the long-wavelength mechanisms. For, in the absence of adapting fields, the test sensitivities of $\pi_{4}$ and $\pi_{3}$ for short-wavelength targets are only slightly lower than those of $\pi_{1}$ and $\pi_{2}$ (WYSZECKI and STILES, 1967, Tables 4.6 and $4 \cdot 8$ ).

We have performed an exploratory experiment that provides some basis for distinguishing these possibilities. The use of an adapting field of high intensity and long wavelength allows us to examine in isolation the response of $\pi_{1}$ to supra-threshold targets. 


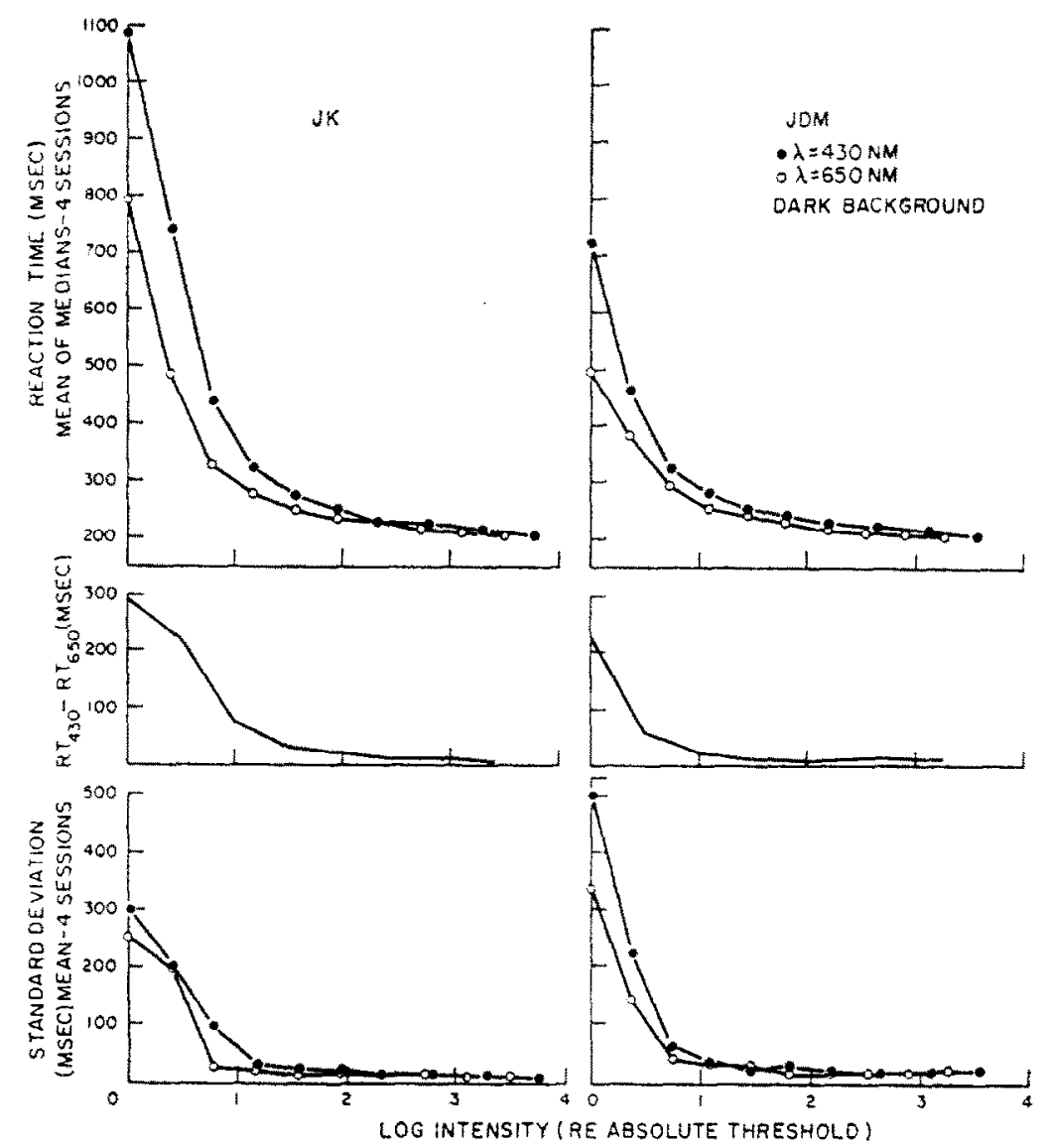

Fig. 5. The upper panels show the relation of reaction time to target intensity when 430 and $650 \mathrm{~nm}$ targets are presented on a dark background. The results are the means of medians for four sessions. Note that reaction times for weak stimuli are longer than those of Experiment 1 owing to the use here of steps rather than pulses. The difference between the values for the two test wavelengths is plotted in the middle panels and the lowernost panels show standard deviations.

\section{EXPERIMENT 4}

430,500 and $550 \mathrm{~nm}$ targets of varying intensity were presented on a $650-\mathrm{nm}$ adapting field. The intensity of the background field remained constant at $-0.5 \log \mathrm{erg} / \mathrm{sec} / \mathrm{deg}^{2}$. Targets subtended $1^{\circ}$ of visual angle and presentation was terminated by the subject's response.

Six separate sessions were devoted to each of the three test wavelengths. Ten stimulus intensities, ranging over approximately $2 \log$ units, were chosen for each wavelength, the lowest value corresponding to the 50 per cent detection threshold for that wavelength. The threshold was estimated by the multiple-staircase, Yes-No procedure; these measurements were made at the beginning of the first session devoted to a particular wavelength.

In each session, reaction times were measured in five blocks separated by $15 \mathrm{sec}$ intervals. Within each block five stimuli were presented at each intensity and the order of intensities was randomized without replacement. Reaction time was measured from the onset of the test-flash and a fresh trial was begun after $2 \mathrm{sec}$ if no response had been made in that interval. In other details the procedure was similar to that of Experiment 3.

The results of Experiment 4 are shown in Fig. 6 . The abscissae represent log stimulus intensity relative to the increment threshold of the wavelength concerned. The responses to $430 \mathrm{~nm}$ targets were mediated by 


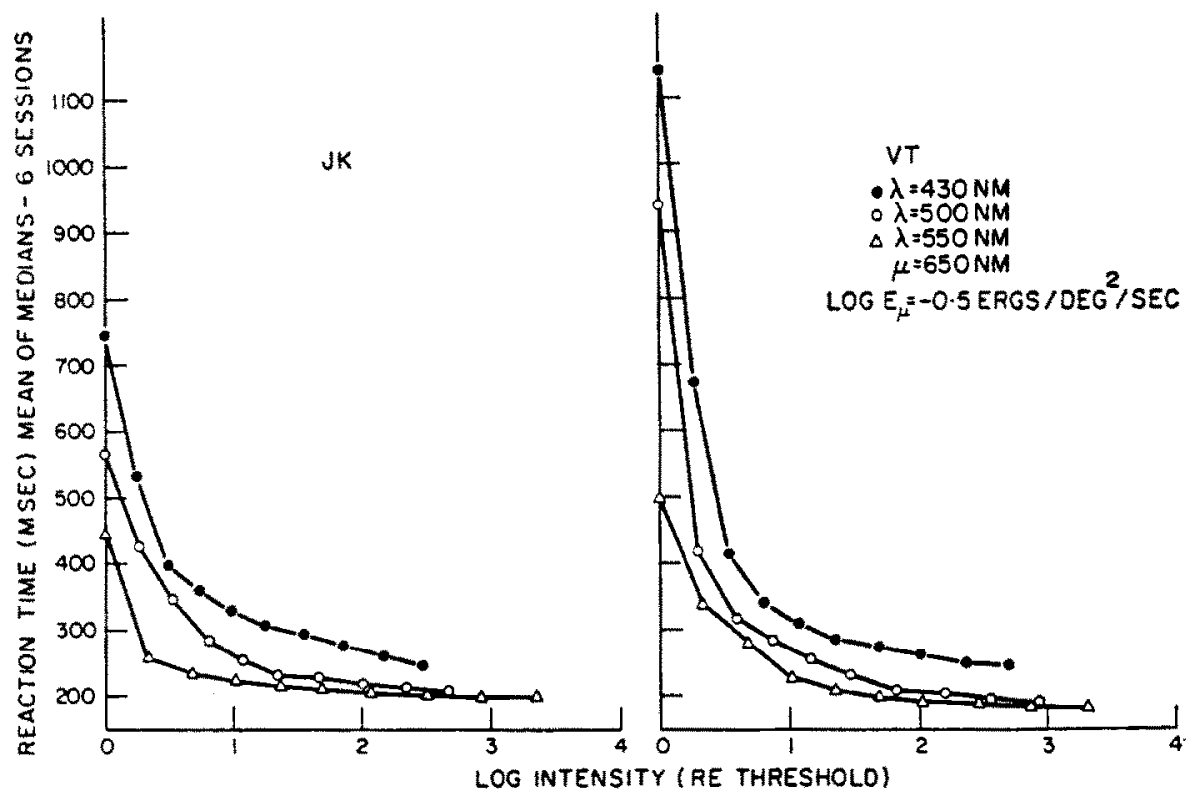

FiG. 6. The relation of reaction time to target intensity when 430,500 and $550 \mathrm{~nm}$ targets are presented on a $650-\mathrm{nm}$ adapting field. The results shown are the means of medians for four sessions.

$\pi_{1}$ alone throughout almost the entire range of intensities used; for, under the adapting conditions of this experiment, the sensitivity of $\pi_{1}$ to $430 \mathrm{~nm}$ test flashes is greater than that of $\pi_{4}$ by approximately 2 decadic units. The response to $550 \mathrm{~nm}$ targets, on the other hand, will be mediated by $\pi_{4}$ throughout much of the intensity range, although the other long-wavelength mechanism, $\pi_{5}$, may also contribute to responses at the highest intensities. The differences between the two functions are clear. Reaction times mediated by $\pi$, do remain substantially longer than those mediated by the long-wavelength mechanisms even at the highest intensities used and there is a strong suggestion that the asymptotes differ by as much as $50 \mathrm{msec}$. Under the adapting conditions of the experiment the sensitivity of $\pi_{1}$ to $500 \mathrm{~nm}$ targets is about $0.5 \mathrm{log}$ units higher than that of $\pi_{4}$ and we suggest that the intermediate form of this function arises because reactions depend primarily on $\pi_{1}$ at low intensities and primarily upon $\pi_{4}$ at high intensities. The similarity of the asymptotic values of the 500 and $550 \mathrm{~nm}$ functions suggests that the slowness of responses to intense $430 \mathrm{~nm}$ targets does not arise merely from a contextual effect, that is, from the presence within an experimental session of extremely long responses to targets of low intensity.

\section{DISCUSSION}

In those studies that have failed to show a relation between wavelength and reaction time we may suppose that the response was mediated throughout the spectrum by the longwavelength mechanisms, $\pi_{4}$ and $\pi_{5}$. In some experiments the blue targets were of an intensity such that the response of $\pi_{4}$ would be faster than that of $\pi_{1}$ and in others the nominally blue targets were of so long a wavelength that even at absolute threshold $\pi_{4}$ would probably be more sensitive than $\pi_{1}$ and $\pi_{2}$. In addition, the use of CFF in the photometric matching of different wavelengths, as in the study of LrT et al. (1971), may yield an experiment that is theoretically circular; for an equation of time constants is hardly an appropriate preliminary to an investigation of reaction times.

\footnotetext{
${ }^{7}$ An exact value cannot be derived from the tabulated sensitivities given by WYSZECK1 and STILEs (1967), owing to individual differences and to the variation of sensitivity with target duration. Although the thresholds for $\pi_{2}$ and $\pi_{3}$ are higher than those for $\pi_{1}$ under the conditions of Experiment 4 , these mechansims may contribute to responses to supra-liminal targets.
} 
The finding that the time constants for the short-wavelength mechanisms are generally longer than those for $\pi_{*}$ and $\pi_{*}$, and especially the general finding that the time constants of the chromatic mechanisms vary independently, do lend partial and qualitative support to one widely-favoured explanation of the subjective colours produced by intermittent stimulation. Thus Pietron held that when Benham's top is observed under achromatic illumination the different cone mechanisms reach their transitory peak response with different latencies. Because the rate of rotation necessary to produce a given hue was inversely related to the level of Humination and because the results for monochromatic lllumination could not be predicted from those for white light, he was further led to assume that the time constants of the several mechanisms were independently related to stimulus intensity (PIERoN, 1923; KLEITMA N and PIÉrov, 1925a,b). Interactions between the temporal characteristics of the stimulus and the time constants of individual $\pi$ mechanisms may also contribute to, if not wholly account for, the hue shifts that arise from intermittent monochromatic stimulation (BARTLEY and NELSON, 1960; NLLSSON and NeLSON, 1971) and from variations in stimulus duration (WeITZMAN and KINNEY, 1967).

Most importantly perhaps, the independence of the time constants of cone mechanisms may explain discrepancies between luminosity functions derived by different methods of heterochromatic photometry. The individual flashes used in flicker photometry may be short relative to the integration times of the various mechanisms and therefore, if these integration times differ, the responses of different mechanisms to a flash of a given duration will represent different proportions of their responses to maintained illumination. It would follow that the results obtained from flicker photometry will depend upon the stimulus frequency used; and it has indeed been reported that results obtained from flicker photometry agree well with those obtained by direct comparison only when the stimuli used in the latter method are of the same duration as the individual flaskes used in flicker photometry (FEREE and RAND, 1915, 1923, 1925). Moreover, if we accept the value of $18 \mathrm{~Hz}$ that is given by BRINDLEY, DU CROZ and RUSHTON (1966) as the maximum CFF for $\pi_{1}$, it would seem that in many studies of flicker photometry the blue-sensitive mechanism may not influence the observer's final adjustments at all, since any contribution that it does make to brightness would here be equivalent to a steady background. In the case of luminosity functions derived from foveal threshold measurements the marked effect of stimulus duration has been demonstrated directly by IKEDA and BOYNTON (1962).

Although the primary comparisons of Experiment 1 suggest that the variations in time constants that arise from variations in adaptive state must be determined at a very distal stage in the visual system, it is of interest to consider the possibility that some of the additional delay associated with the short-wavelength mechanisms arises not from a difference between individual $\pi$ mechanisms but from a general difference between chromatic and luminosity channels in the visual system. All versions of the trichromatic theory have assumed that the blue or violet fundamental makes little or no contribution to brightness. GUTH (1968), for example, while suggesting that direct judgements of brightness depend upon both the "opponent" and "non-opponent" channels of the primate visual system, has proposed that the non-opponent system receives no input at all from cones sensitive to short wavelengths. The signals from $\pi_{1}$, then, may be confined to the chromatic channels and the

\footnotetext{
Why the $\pi_{1}$ signals should be excluded from the non-opponent channel would be a matter for biological speculation. It is possible that not only the temporal, but also the spatial, resolution of the non-opponent system is higher and that an input from blue-sensitive cones would actually be disadvantageous owing to chromatic aberration and the stattering of short-wavelength light within the eye. Alternatively, intrinsic temporal properties of $\pi_{1}$ might themselves be the cause of its exclusion.
} 
very possibility of flicker photometry suggests that these channels have a lower temporal resolution than the luminosity channels. DE LANGE (1958b) and REGAN and TYLER (1971a) have demonstrated formally the separation of the threshold vs. frequency functions for luminance modulation and for wavelength modulation; and similarly REGAN and TYLER (1971b) have shown that the critical duration for the detection of brief changes in wavelength is longer at all wavelengths than the conventional critical duration for luminance increments. There is some electrophysiological evidence for the existence of brightness and chromaticity channels with different temporal response properties and also for the exclusion of $\pi_{1}$ signals from the luminosity system. In a sample of on-centre ganglion cells in the retina of the rhesus monkey Gouras (1968) found that non-opponent "phasic" units, which respond only transiently to maintained stimuli, received input from red-and green-, but not from blue-sensitive cones; a short-wavelength input, from a cone mechanism resembling $\pi_{1}$, was found only in "tonic" units, which respond continuously to maintained stimuli and which are organised in a spectrally and spatially antagonistic manner.

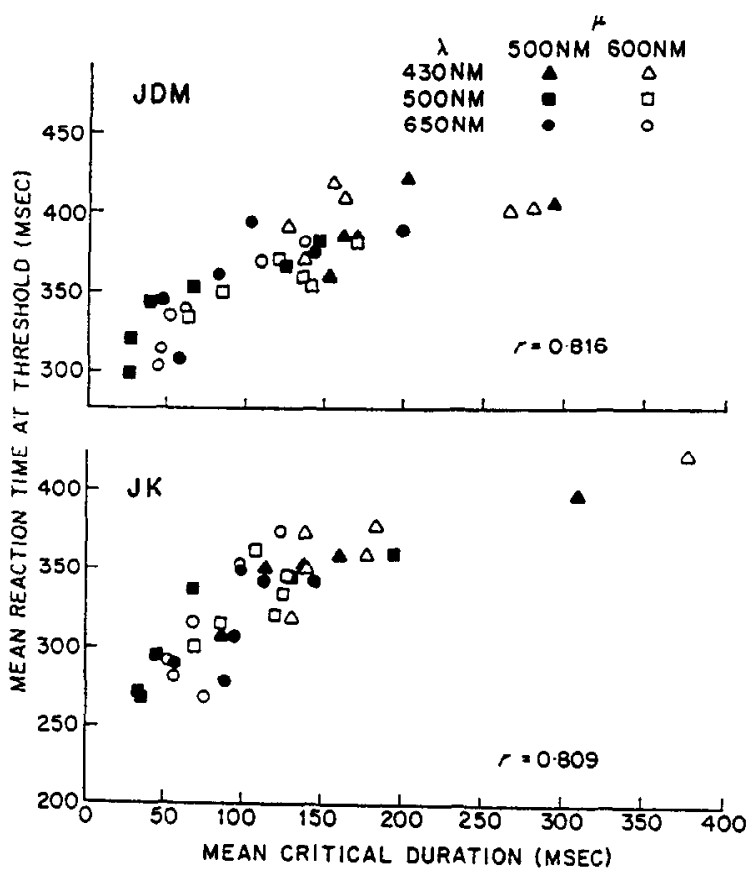

FIG. 7. Correlation of mean reaction time and mean critical duration. Values for reaction times are taken from Experiment 1 of the present paper and values for critical durations are taken from KRAUSKOPF and MOLLON (1971).

Finally, what can be concluded about the value of reaction times in the study of retinal processes? Figure 7 shows the relation between the reaction times obtained in Experiment 1 of the present study and the critical durations (here plotted in linear units) obtained for the corresponding conditions in an earlier experiment (KRAUSKOPF and MOLLON, 1971). There was an interval of three months between the two experiments. The correlation coefficients are 0.816 and 0.809 for JDM and JK respectively. The good correlation of these very different measures suggests that they are determined by the same properties of the system and 
also strengthens the assumption, made above, that the non-sensory components of the reaction time are essentially independent of the stimulus parameters that were varied in Experiment 1. However, one discrepancy should be noted between results obtained from reaction times and those obtained from measures of temporal integration: critical durations remain the same (BAUMGARDT and HILLMAN, 1961), or possibly increase (BARLOW, 1958), as stimulus area is reduced, whereas the reaction times found for small targets in Experiment 2 of the present study are substantially shorter than those found for $1^{\circ}$ targets in Experiment 1 . It is possible that eye movements during very long flashes contaminate the measurement of critical durations. Since reaction time to very brief flashes cannot be influenced by eye movements, there may be circumstances under which this measure provides a superior estimate of the temporal properties of the visual system.

Acknowledgements-We are indebted to G. Arden, D. I. A. MacLeod, F. H. C. Marriott and S. SternberG for critical discussion and to VIRGINIA TURNER and W. KROPFL for experimental assistance. The experiments described above were performed at Bell Laboratories. The first author is supported by a grant from the Medical Research Council of Great Britain.

\section{REFERENCES}

AlPERn, M. (1968). A note on visual latency. Psychol. Rev. 75, 260-264.

BARLow, H. B. (1958). Temporal and spatial summation in human vision at different background intensities. J. Physiol., Lond. 141, 337-350.

BARTLEY, S. H. and NeLSON, T. M. (1960). Certain chromatic and brightness changes associated with rate of intermittency of photo-stimulation. J. Psychol. 50, 323-332.

Baumgard, E. and Hilliman, B. (1961). Duration and size as determinants of peripheral retinal response. J. opt. Soc. Am. 51, 340-344.

BRINDLEY, G. S. (1954). The summation areas of human colour-receptive mechanisms at increment threshold. J. Physiol., Lond. 124, 400-408.

Brindery, G. S., DU Croz, J. J. and Rushton, W. A. H. (1966). The flicker fusion frequency of the bluesensitive mechanism of colour vision. J. Physiol., Lond. 183, 497-500.

Charpentier, A. (1893). Démonstration directe de la différence de temps perdu suivant les couleurs. Arch́s Physiol. Ser. 5, 5, 568-570.

COHEN, J. and Gordon, D. A. (1949). The Prevost-Fechner-Benham subjective colors. Psychol. Bull. 46, 97-136.

DE LANGE, H. (1958a). Research into the dynamic nature of the human fovea-cortex systems with intermittent and modulated light. I. Attenuation characteristics with white and coloured light. J. opt. Soc. Am. $48,777-784$.

DE LANGE, H. (1958b). Research into the dynamic nature of the human fovea-cortex systems with intermittent and modulated light. II. Phase shift in brightness and delay in color perception. J. opt. Soc. Am. 48, 784-789.

FEREE, C. E. and RAND, G. (1915). A preliminary study of the deficiencies of the method of flicker for the photometry of lights of different color. Psychol. Rev. 22, 110-162.

FereE, C. E. and RAND, G. (1923). Flicker photometry. Trans. Illum. Eng. Sci. 18, 151-207.

FEREE, C. E. and RAND, G. (1925). The agreement of flicker and equality-of-brightness photometry when the same lengths of exposure are used in both methods. Am. J. Psychol. 36, 188-191.

Fuortes, M. G. F. and HodGKr, A. L. (1964). Changes in time scale and sensitivity in the ommatidia of Limulus. J. Physiol., Lond. 172, 239-263.

Gouras, P. (1968). Identification of cone mechanisms in monkey ganglion cells. J. Physiol, Lond. 199, 533-547.

GUTH, S. L. (1964). The effect of wavelength on visual perceptual latency. Vision Res. 4, 567-578.

GUTH, S. L. (1969). On luminance additivity and related topics. Vision Res. 9, 537-575.

Helmiolitz, H. (1922). Physiological Optics, Optical Society of America, Vol. 2, p. 258.

HERRICK, R. M. (1956). Foveal luminance discrimination as a function of the duration of the decrement or increment in luminance. J. comp. physiol. Psychol. 49, 437-443.

HOLMEs, J. L. (1926). Reaction time to photometrically equal chromatic stimuli. Am.J. Psychol. 37, 414-417.

IKEDA, M. and BOYNTON, R. M. (1962). Effect of test-flash duration upon the spectral sensitivity of the eye. J. opt. Soc. Am. 52, 697-699.

IVES, H. E. (1917). Visual diffusivity. Phil. Mag. 33, Ser. 6, 249, 13-33.

IVEs, H. E. (1918). The resolution of mixed colours by differential visual diffusivity. Phil. Mag. 35, Ser. 6, 251, 413-421. 
Kleitman, N. and PiÉRon, H. (1925a). De l'existence de constantes spécifiques différentes pour les radiations chromatiques fondamentales dans l'établissement de la sensation lumineuse par excitation exclusive des cònes rétiniens. C. Séanc. Soc. Biol. 112, 26-29.

Klertman, N. and Préron, H. (1925b). Recherches sur l'établissement de la sensation lumineuse. Année. psychol. 25, 34-84.

KRAUSKOPF, J. (1969). Variation of critical duration of red and green cone receptors with chromatic adaptation. J. opt, Soc. Am. 59, 504 (Abstr.).

KRAUSKOPF, J. and Molzon, J. D. (1971). The independence of the temporal integration properties of individual chromatic mechanisms in the human eye. J. Physiol., Lond. 219, 611-623.

LiANG, T. and PréRON, H. (1947). Recherches sur la latence de la sensation lumineuse par la méthode de l'effect chronostéréoscopique. Année psychol. 43-4, 1-53.

Lit, A., Young, R. H. and Shaffer, Margaret. (1971). Simple reaction time as a function of luminance for various wavelengths. Percept. \& Psychophys. 10, 397-399.

MATIN, L. (1968). Critical duration, the differential luminance threshold, critical flicker frequency and visual adaptation: a theoretical treatment. J. opt. Soc. Am. 58, 404-415.

Nilsson, T. H. and Nelson, T. M. (1971). Hue shifts produced by intermittent stimulation. Vision Res. 11, $697-712$.

PTÉRON, H. (1923). Le mécanisme des couleurs subjectives de Fechner-Benham. Année psychol. 23, 1-49.

Préron, H. (1932a). Les lois du temps du chroma. Report of a Joint Discussion on Vision, pp. 277-280. The Physical Society, London.

PrÉRoN, H. (1932b). La sensation ehromatique. Donnés sur la latence propre et l'établissernent des sensations de couleur. Année psychal. 32, 1-29.

PollaCK, J. D. (1968). Reaction time to different wave-lengths at various luminances. Percept. \& Psychophys. 3, 17-24.

REGAN, D. and TYLER, C. W. (1971 a). Some dynamic features of colour vision. Vision Res. 11, 1307-1324.

REGAN, D. and TYLER, C. W. (1971b). Temporal summation and its limit for wavelength changes: an analog of Bloch's Law for color vision. J. opt. Soc. Am. 61, 1414-1421.

Sperling, G. and Sondm, M. M. (1968). Model for luminance discrimination and flicker detection. J. opt. Soc. Am. 58, 1133-1145.

STERNBERG, S. and KNOLL, R. L. (1972). The perception of temporal order: fundamental issues and a general model. In Attention and Performance IV (edited by S. KoRNBLUM). Academic Press, New York.

STILES, W. S. (1939). The directional sensitivity of the retina and the spectral sensitivities of the rods and cones. Proc. R. Soc. B. 127, 64-105.

StILES, W. S. (1949). Increment thresholds and the mechanisms of colour vision. Documenta ophth. 3, 138-163.

Strles, W. S. (1953). Further studies of visual mechanisms by the two-colour threshold technique. In Coloquio sobre problemas opticos de la vision. pp. 65-103. Union Internationale de Physique Pure et Appliquée, Madrid.

STILES, W. S. (1959). Colour vision: the approach through increment-threshold sensitivity. Proc. natn. Acad. Sci. U.S.A. 45, 100-114.

UETSUKI, T. and IKEDA, M. (1971), Adaptation and critical duration for Stiles $\pi$ mechanisms. J. opt. Soc. Am. $61,821-828$.

WALRAVEN, P. L. and LEEBeEK, H. J. (1964). Phase shift of sinusoidally alternating coloured stimuli. J. opt. Soc. Am. 54, 78-82.

WemZMAN, D. O. and KINNEY, J. A. S. (1967). Appearance of color for small, brief, spectral stimuli, in the central fovea. J. opt. Soc. Am. 57, 665-670.

WyszeckI, G. W. and SmLes, W. S. (1967). Color Science, Concepts and Methods, Quantitative Data and Formulas. Wiley, New York.

\footnotetext{
Abstract-The old question of whether visual latency varies with wavelength has been reexamined by isolating individual $\pi$ mechanisms. Reaction times were recorded to monochromatic increments presented on monochromatic adapting fields and it was found that the tim : constants of each colour mechanism vary independently according to the sensitivity of the mechanism concemed and do not depend upon the adaptive state of the retina as a whole. This independence may partially explain discrepant results in heterochromatic photometry and distortions of hue that arise from brief or intermittent stimulation. A correlation between the present results and the corresponding critical durations demonstrates the value of reaction times in the study of visual processes.
} 
Résumé-Le rapport examine, par la méthode disolation des mécanismes ' $\pi$ ' individuels, l'ancien problème d'une dépendance de la latence visuelle de la longueur d'onde des stimulations lumineuses. On a mesuré les temps de reaction pour des accroissements monochromatiques apparaissants sur des fonds monochromatiques et on a trouve que les constantes de temps de chaque mécanisme chromatique varient indépendamment selon la sensibilité du mécanisme en question et ne dépendent pas du niveau d'adaptation de la rétine en totalite. Peut-être cette indépendance explique-t-elle en partie les résultats contradictoires dans la photométrie hétérochrome er les déformations de couleur qui sont produites par une excitation courte ou intermittente. Une corrélation entre les résultats actuels et les durées critiques qui y correspondent démontre la valeur des temps de réaction pour l'étude des processus visuels.

Zusammenfassung-Die alte Frage, ob die Empfindungszeit sich der Lichtwellenlänge gemäss ändert, ist wieder untersucht worden, indem man individuelle $\pi$ Mechanismen isoliert hat. Reaktionszeiten auf monochromatische Inkremente, die plotzlich auf monochromatischen Adaptationsfeldern aufleuchteten, wurden gemessen, und es stellte sich heraus, dass die Zeitkonstanten der verschiedenen Farbenmechanismen sich je nach der Empfindlichkeit des betreffenden Mechanismus voneinander unterscheiden, und also nicht vom Adaptationszustand der Netzhaut als Ganzem abhängen. Diese Unabhängigkeit mag die Diskrepanzen, die bei der heterochromen Photometrie auftreten, wenigstens zum Teil erklären, und vielleicht auch zum Verständnis der Verschiebungen der Farbwerte beitragen, die bei kurzdauernder oder unterbrochener Reizung erscheinen. Die Korrelation zwischen den heir erhaltenen Ergebnissen und den entsprechenden kritischen Zeitspannen weist auf die Rolle hin, die die Messung der Reaktionszeiten bei der Erforschung der Sehvorgänge spielen kann.

Резюме-При помоши изолирования отдельных П механизмов рассмотрен наново старый вотрос о возможности измененыи латентности с длиной волны. Регистрировались значения времени реакции на монохроматические приросты, подаваемые на монохроматипеских полях адапии, и было найдено, что константы времени каждого цветного механизма нзменяются независкмо, смотря по чувствительности данного механизма, п не завнсят от адаптивного состояния сетчатой оболочки в целости. Эта независимость может быть частнчным обълснендем расхождений результатов в гетерохроматической фотометрин и пскажендй цвета при кратковременном иля прерывистом возбухденки. Связь между поученными результатами м соответствуюшими критическими значениями продолхительности указывает на ценность учета времен реакция в изучении процессов зрения. 